DOI 10.37882/2223-2982.2020.10-2.10

\title{
ФРАЗЕОЛОГИЧЕСКИЕ ЕДИНИЦЫ С КОМПОНЕНТОМ ЦВЕТООБОЗНАЧЕНИЯ (НА МАТЕРИАЛЕ АЗЕРБАЙДЖАНСКОГО ЯЗЫКА)
}

\section{PHRASEOLOGICAL UNITS WITH COLOR-CODE COMPONENT (ON THE MATERIAL OF THE AZERBAIJAN LANGUAGE)}

\section{Ismayilova \\ M. Driga}

Summary: The article is devoted to the study of semantic features phraseological units with a component «color» (based on the Azerbaijani language). The article contains phraseological units with a component white. PUs reveal the mentality, national characteristics, the inner world of Azerbaijanis in various everyday situations.

Keywords: language, culture, phraseological units, white color, light, joy.
Исмайлова Лейлаханум Гусейн кызы

К.филол.н., дочент, Военный университет МО РФ (Москва)

Leylaxanum@mail.ru

Дрига Марина Владимировна

Старший преподаватель, Военный университет МО РФ

(Москва)

Dr_mari@mail.ru

Аннотация: Статья посвящена исследованию фразеологических единиц с компонентом «цвет» (на материале азербайджанского языка). В статье собраны фразеологические единицы с компонентом белый цвет. ФЕ раскрывают менталитет, национальные особенности, внутренний мир азербайджанцев в различных бытовых ситуациях.

Ключевые слова: язык, культура, фразеологические единицы, белый цвет, свет, радость.
Я зык является орудием общения, выражения чувств, мыслей, отношений между людьми. Современная лингвистика рассматривает язык как «культурный код нации», а не только как средство общения [Маслова 2001: 3]. Язык отражает реальность и интерпретирует ее, создавая особую картину мира. Языковая картина мира - это «отображение в формах языка устройства в экстралингвистической действительности, что в свою очередь проявляется в объеме значения и внутренней форме языковых единиц» [Гак 2000: 36].

«Язык теснейшим образом связан с культурой: он прорастает в нее, развивается в ней и выражает ее» [Маслова 2001: 9]

Благодаря языку человек может выражать свои чувства, эмоции, волнения и переживания. Как говорил Гумбольдт: «Нет ничего внутри человека настолько глубокого, настолько тонкого и всеобъемлющего, что не переходило бы в язык и не было бы через его посредство познаваемым» [Гумбольд 1984: 57]

Большая сила кроется в языке. Благодаря ему человек может передать свои самые сокровенные чувства, благодаря ему может понять ближнего и помочь ему.

Азербайджанцы по своей природе очень эмоциональны. Может, именно поэтому в языке существует много фразеологических единиц, буквально на любой случай жизни существует своя фразеологическая единица.
При этом каждая из этих единиц имеет многочисленные варианты, синонимы и антонимы.

Фразеологические единицы создавались в языке годами, они связаны с определенными историческими, географическими, бытовыми, обрядовыми, традиционными моментами. Поэтому каждая фразеологическая единица имеет свою историю происхождения. Они откладываются в сознании и остаются в памяти поколений. Носители языка чувствуют, в какой момент уместно употребить ту или иную фразеологическую единицу. Конечно, можно их заменить обычными словами, но вся красота, вся прелесть в том, что фразеологизмы придают речи образность, эмоциональность, красочность.

В азербайджанском языке много фразеологических единиц, обозначающих цвета. Цвет несет огромный смысл в культуре и жизни человека. Благодаря цветам многие народы выражают свои эмоции, настроение, раскрывают свой менталитет.

Значения цветов играют важную роль. Например, в большинстве случаев белый цвет символизирует счастье, свет, радость, чистоту, справедливость. Тем не менее, встречаются в речи фразеологические единицы также и с отрицательным смыслом.

Ağ gün [досл.: белый день] счастливая жизнь. Например: Səni ağ günә çıxasan // Чтобы ты счастливой стала. 
Ağ gün ağardar [досл.: белый день осветлит] в народе говорят, счастье делает человека светлым. Например: $\boldsymbol{A g ̆}$ gün ağardar, qara gün qaraldar. // Счастливый человек белеет, а несчастный чернеет.

Ağ günə çıxmaq - стать счастливой.

Например: Sonanın qızı ağ günə çıxdı. // Дочь Соны стала счастливой.

Ağa ăg, qaraya qara demək [досл.: белое называть белым, черное называть черным] // называть вещи своими именами. Например: О heç zaman ağa qara deməz // Она никогда белое черным не назовет.

Ağı qaradan seçməmək [досл.: белое от черного не уметь отличать] // не уметь различать хорошее от плохого. Например: Mәriyəm hələ balacadır, ağı qaradan seçə bilmir. Мариям еще маленькая, и не может отличить хорошее от плохого.

Ağına-qarasına baxmadan [досл.: не смотреть ни на белое, ни на черное] не обращая ни на что внимание, как попало, без всякого разбора сделать что-нибудь. Например: Ağına-qarasına baxmadan

bilet alıb getdi. // Несмотря ни на что, купила билеты и уехала.

Ağsaqqallıq etmək // быть старостой, быть наставником, принять на себя ответственность руководить. Например: Әli bu mərəkədə ağsaqqallıq edir. // Али на этом собрании является старостой.
Ağ at arpa yeməz? [досл.: белый конь ячмень не ест] // мышиный жеребчик.

Ağ bayraq qaldırmaq [досл.:поднять белый флаг] сдаваться. Например: Әskərlər ăg bayraq qaldırdılar. // Солдаты сдались, подняли белый флаг.

Ağ böhtan [досл.:белая клевета] чистейшая клевета. Hапример: Sən utanmırsan, axı bu ağ böhtandır. //Тебе не стыдно, ведь это чистейшая клевета.

Ağ eləmək [досл.: делать белое] // перегибать палку, переходить все границы, наглеть. Например: Sәn lap ăg elədir. //Ты совсем перешел все границы.

Ağdan qaraya söz deməmək [досл.: от белого черному ни слова не говорить] потакать, не обижать. Haпример:Bu balaca qızı çox pis tərbiyə edirlər, Ağdan qaraya söz demirlər. Эту маленькую девочку плохо воспитывают, во всем ей потакают.

Gözünün ağı - qarası [досл.:белое и черное его глаза] один единственный ребенок. Hanример: Lalə mənim gözümün ağı-qarası bir dənə qızımdır. Лала моя единственная дочь.

Изучение фразеологических единиц представляется нам чрезвычайно важным, поскольку в лексических формулах находят свое яркое выражение история и культурные коды народа, его традиции, мораль, привычки и обряды. Проведенное исследование в значительной степени подтверждает и иллюстрирует это утверждение.

\section{ЛИТЕРАТУРА}

1. Гак В.Г. Русская динамическая картина мира // Русский язык сегодня. Вып. 1 / под ред. Л.П. Крысина. - М.: «Азбуковник», 2000. - С. 36-44.

2. Маслова В.А. Лингвокультурология: Учеб. пособие для студ. высш. учеб, заведений. - М.: Издательский центр «Академия», 2001. - 208 с. 